\title{
CHEIAS NA AMAZÔNIA: ESTUDO SOCIOAMBIENTAL NA CIDADE DE TEFÉ - AM
}

\author{
Amanda Caroline Cabral da Silva \\ Mestre pelo Programa de Pós-graduação em Geografia - UFAM \\ Universidade Federal do Amazonas \\ mandinha.geo.cabral@gmail.com
}

José Alberto Lima de Carvalho Professor Doutor do Programa de Pós-graduação em Geografia - UFAM Universidade Federal do Amazonas- UFAM albertogeografo@gmail.com

\begin{abstract}
RESUMO: Um dos fatores natural na organização do espaço e na vida dos moradores ribeirinhos na Amazônia é a sazonalidade de seus rios. Na medida em que aumenta a população dispersa concentrada em núcleos urbanos, associados a cheias cada vez maiores, aumenta também em escala proporcional os problemas socioambientais, com é o caso da cidade de Tefé, localizada no Médio Solimões. O presente estudo teve como objetivo analisar os impactos causados pelas cheias na cidade de Tefé. Embora seja um fenômeno natural na região amazônica, as cheias estão cada vez maiores e mais frequentes, tornando- se um problema de ordem socioambiental para os habitantes das margens dos rios amazônicos. Para o desenvolvimento da mesma foi elaborado referencial teórico-metodológico e realizados trabalhos de campos. A partir do mesmo foi identificado os impactos causados pelas cheias, cujo existe um aglomerado de pessoas que, por necessidade e falta de controle das instituições públicas, ocupam áreas de controle do rio de forma indevida, vindo a sofrer as consequências dos mesmos durante o transbordamento.
\end{abstract}

Palavras-chave: Regime hidrológico, Impactos socioambientais, Ocupações Irregulares.

\section{INTRODUÇÃO}

As cheias na Amazônia, principalmente as excepcionais não obedecem às estações do ano como nas médias e altas latitudes. O regime hidrológico apresenta em apenas dois períodos anuais na região sendo a cheia e vazante, a mesma acontece em períodos diferentes que começa em outubro/novembro e vai até junho (cheia) e julho a outubro/novembro (vazante). Nesse sentido, as cheias são consideradas atualmente um dos problemas de ordem socioambiental para os habitantes das margens dos rios amazônicos, as inundações têm cada vez mais chamado a atenção da sociedade, causando impactos econômicos e sociais ANA $^{1}$ (2010). Sobretudo, é importante salientar que estes impactos podem ser considerados "socioambientais", uma vez que altera a qualidade de vida da população e provoca uma série de implicações nas cidades amazônicas. O presente trabalho parte de um estudo socioambiental, o objetivo foi analisar os impactos causados pelas cheias e seus efeitos na cidade de Tefé.

\footnotetext{
${ }^{1}$ Agência Nacional de Águas, doravante como citação.

REVISTA GEONORTE, V.9, N.33, p.170-174, 2018.

DOI: 10.21170/geonorte.2018.V.9.N.33.170.174

(ISSN 2237 - 1419)
} 
CHEIAS NA AMAZÔNIA: ESTUDO SOCIOAMBIENTAL

\section{MATERIAIS E MÉTODOS}

O presente estudo, foi direcionado a partir do levantamento e revisão do referencial teórico, de cunho geral e regional a partir de visitas a bibliotecas e bancos de dissertações, teses e artigos científicos. Além do levantamento bibliográfico, foi realizado pesquisas de campo e coleta de dados. As visitas em campo foram com o objetivo de identificar, fotografar, georreferenciar os pontos das áreas que são atingidas pelas cheias e realizar entrevistas abertas e fechadas com moradores, comerciantes e feirantes para averiguação dos efeitos das cheias na cidade Tefé. O levantamento das análises foi realizado no período de outubro de 2016 a março de 2018. Optamos a partir do conceito de Paisagem neste estudo, sendo ela uma categoria de análise geográfica, onde a partir dela é visto a relação entre sociedade e natureza que integra tantos os elementos naturais como sociais e econômicos nos períodos de cheias, sobretudo das excepcionais na Amazônia. Nesse sentido, buscou-se por base a abordagem sistêmica como método. Para Lopes et.al (2014) o método geossistêmico promove e estimula o estudo integrado a paisagem geográfica, uma vez que as inter-relações dos elementos físicos, biológicos e antrópicos se faz presente.

\section{A RELAÇÃO DA POPULAÇÃO RIBEIRINHA E URBANA COM O REGIME HIDROLÓGICO}

Para Carvalho (2006) o regime hidrológico do rio Amazonas resulta fundamentalmente do regime pluviométrico, sendo muito irregular espacial e temporalmente na região. A relação da população urbana com a variação do nível do rio é um processo que existe há muito tempo, pois ocorre anualmente com a enchente e vazante dos rios.

As dinâmicas das cidades mudam completamente e as condições de vida das populações rurais e urbanas caminham juntos a estas mudanças. Sternberg (1998) aponta que, a subida e descida das águas, afetam a vida da comunidade profundamente. Assim sendo, as cidades situadas nas margens dos rios convivem com esta realidade.

Aguiar (1995) considera que a região apresenta apenas dois períodos anuais: um chuvoso e outro de estiagem. Esses períodos não acontecem ao mesmo tempo. Enquanto os rios da margem direita da bacia de drenagem estão em período de chuva (novembro/dezembro a maio) os da margem esquerda estão em estiagem. A essa diferença espaço-temporal, conhecida como "fenômeno da interferência" é que 


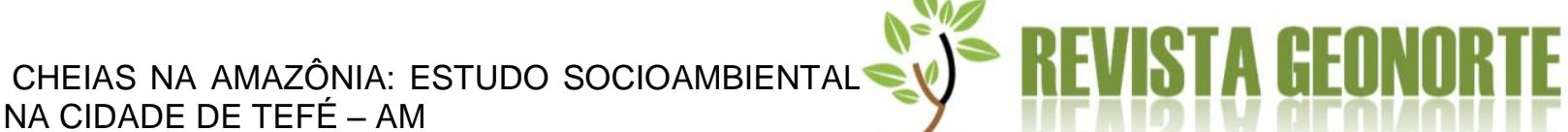

define um regime hidrológico único de cheia e vazante para o rio Amazonas (CARVALHO, 2006).

Embora as populações ribeirinhas estejam adaptadas a essa sazonalidade, as mesmas passaram a sofrer cada vez mais as consequências das inundações à medida que as grandes cheias e as excepcionais se intensificaram a partir da década de 1970, forçando mudanças nas suas condições de vida (PINTO et al, 2009). Além disso, no norte da Amazônia, o País enfrentou uma cheia que superou em alguns lugares, os máximos históricos registrados ANA (2010). No entanto, não apenas as populações dispersas ao longo dos rios têm sofrido com as inundações, como também a população urbana.

\section{RESULTADOS E DISCUSSÃO}

De acordo com os levantamentos e estudos que foram feitos, os impactos identificados foram: (Lixos dentro de casas, riscos de doenças através da água contaminada, mal cheiro, perdas como: bens materiais, animais e documentos), oriundos dos efeitos das cheias na cidade de Tefé, visto que o uso inadequado do solo urbano é um dos principais problemas socioambientais na cidade. Nos períodos de cheias afeta a qualidade de vida e o bem-estar da população, pois os mesmos habitam em áreas planas, ou seja, áreas mais baixas da cidade localizadas próximos ao rio Tefé "lago de Tefé" e do Igarapé Xidarini. Neste período, poucos moradores se retiram do local e se direcionam a casa de familiares (parentescos), ao contrário da maioria, pois vivem no ambiente mesmo alagado por não terem condições financeira, isto faz, a permanência dos moradores nas casas e a construção de um outro assoalho "piso" (Figura 1).

\section{Figura 1- Variação hidrológica- Período de cheia e vazante}

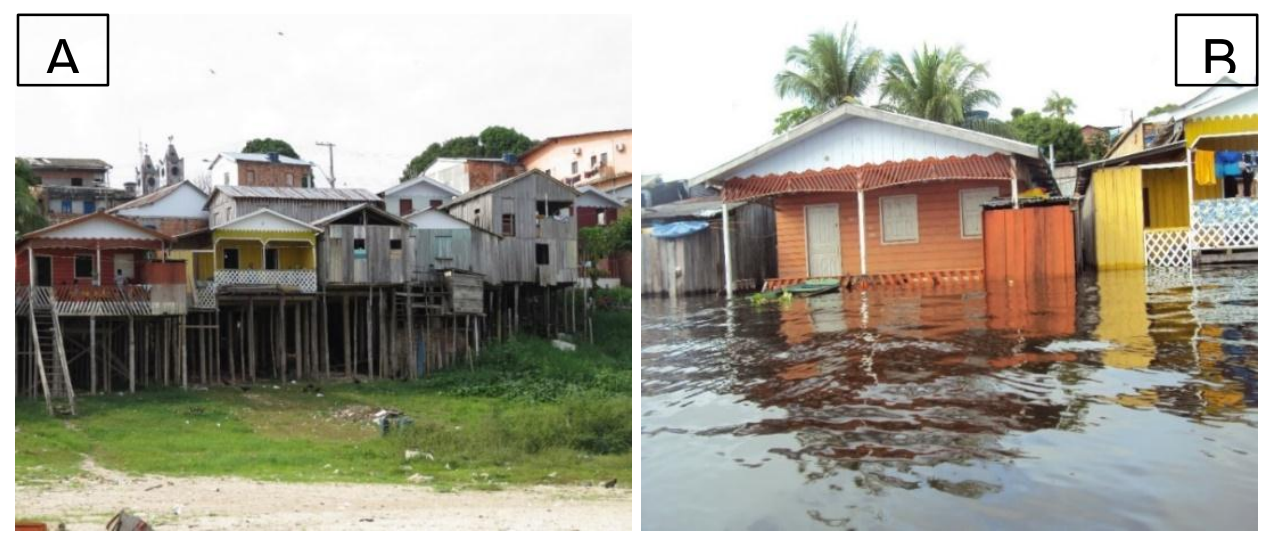

Foto: SILVA, A. C.C. (2016). A- Período de vazante; B- SILVA, A. C. C. (2015). Período de cheia. 
CHEIAS NA AMAZÔNIA: ESTUDO SOCIOAMBIENTAL NA CIDADE DE TEFÉ - AM

Parte das habitações são encontradas em área de risco, quando as cheias são mais elevadas há transbordamentos nos bairros, centros comercias e a feira do município. É visto que a população sofre transtornos nessas áreas, não somente pelas cheias como também o deslizamento de terras. Segundo os moradores um dos maiores impactos causados pelas cheias são o banzeiro, presença de animais peçonhentos (cobras) e a locomoção principalmente para as crianças frequentarem as escolas. Contudo foi visto uma grande preocupação quanto às crianças, justo pelo dobro de atenção dos pais para o cuidado necessário. Portanto, as cheias do rio Solimões/Amazonas, tem causado grandes prejuízos para a população da área urbana, vítimas de cheias no município de Tefé, acarretando impactos ambientais, econômicos e sociais.

\section{CONCLUSÕES}

Diante dos resultados verificamos que, a dinâmica natural do rio Amazonas (cheias) tornou-se um problema de ordem socioambiental, a cidade é tomada pela elevação das águas, inundando casas, ruas e principalmente bairros situados em áreas planas, alterando a qualidade e a vida da população, parte delas habitam em áreas de risco. Contudo, um dos grandes problemas que Tefé vem enfrentando quanto a questão ambiental é oriundo ao processo de urbanização que são as quantidades de ocupação irregular localizadas próximas as margens dos rios que drenam a rede hidrográfica composta pelo lago de Tefé e o Igarapé Xidarini. Nestes, não existe nenhuma atenção do poder político e de maneira alguma satisfazendo a necessidade da população. Portanto, deve ser considerado que o aumento do impacto socioambiental em na cidade de Tefé é consequente do aumento dos moradores nas áreas de risco associado as cheias cada vez maiores e mais frequentes, transformando a paisagem urbana em cenários caóticos, pois as irregularidades habitacionais em Tefé encontram-se situadas em áreas de risco ambientemente alagáveis.

\section{AGRADECIMENTOS}

A Fundação de Amparo à Pesquisa do Estado do Amazonas (FAPEAM), e ao Programa de Pós-Graduação em Geografia (UFAM) pela bolsa concedida e por ter aberto o caminho para o prosseguimento desta pesquisa.

\section{REFERÊNCIAS}


CHEIAS NA AMAZÔNIA: ESTUDO SOCIOAMBIENTAL NA CIDADE DE TEFÉ - AM

ANA- Agência Nacional de Águas. Disponível em: <http://www2.ana.gov.br/Paginas/default.aspx>. Acesso em: 29/08/2016.

AGUIAR, F. E. O. As alterações climáticas em Manaus no século XX. Dissertação (Mestrado em Ciências) - Universidade Federal do Rio de Janeiro, Rio de Janeiro, 1995.

CARVALHO, J. A. L. Terras caídas e consequências sociais: Costa do Miracauera, Paraná da Trindade, Município de Itacoatiara-AM. Dissertação (Mestrado no Programa de Pós-Graduação Sociedade e Cultura na Amazônia do Instituto de Ciências Humanas e Letras) - Universidade Federal do Amazonas. Manaus, 2006, $142 p$.

LOPES, L.G.N; SILVA, A.G; GOURLART, C. O. Novos caminhos na análise integrada da paisagem. Natureza on line 12(4): 156-159, 2014.

STERNBERG. H. O’ R. A água e o homem na várzea do Careiro- $2^{\circ}$ Ed.- Belém: Museu Paraense Emílio Goeldi, 1998.

PINTO, A. G. N. et al. As grandes enchentes do Amazonas, na década de 1970, e sua associação com a migração para Manaus. Reunião Regional da SBPC em Tabatinga- Tabatinga/ AM- $2009 . \quad$ Ou $<$ http://www.sbpcnet.org.br/livro/tabatinga/resumos/134.htm> Acesso em: $10 / 06 / 2017$. 